\title{
Is the Severity of the Penalty an Effective Deterrent? A Strategic Approach for the Crime of Tax Evasion
}

\author{
Bruno Chiarini \\ Elisabetta Marzano
}
CESIFO WORKING PAPER NO. 6112
CATEgory 6: Fiscal Policy, MaCroeconomics and GROWTH
SEPTEMBER 2016
An electronic version of the paper may be downloaded
- from the SSRN website:
- from the RePEc website:
- from the CESifo website:
www.SSRN.com
www.RePEc.org
www.CESifo-group.org/wp




\title{
Is the Severity of the Penalty an Effective Deterrent? A Strategic Approach for the Crime of Tax Evasion
}

\begin{abstract}
In order to analyze the severity of sentencing, and to show how the probabilistic interpretation of strategic behavior can be tricky, this paper uses the crime strategic model (inspection game) proposed by Tsebelis. This model shows that any attempts to increase the severity of punishment will alter the payoff of the individuals involved, leaving unchanged the frequency of violation at equilibrium. This result is misleading: payoffs are not independent and the crime game can not be simply read with mixed strategies. These are inconclusive on how the players act rationally. This is undeniably true for the crime of tax evasion, where the dishonest taxpayers are rational agents, motivated by the comparison of payoffs, considering the risk of breaking the law. Although an irreducible minimum of uncertainty remains, the Nash equilibrium in mixed strategies provides us with the necessary information on equilibria in pure strategies that will be played. In this context, tougher sentencing deters crime, although, as the Italian historical experience teaches, the necessary condition required is the certainty of punishment and the ability of the government to enforce it.
\end{abstract}

JEL-Codes: C720, H260, K420.

Keywords: crime game, tax evasion, deterrence, severity of punishment.

Bruno Chiarini

Department of Economic and Legal Studies University of Naples, Parthenope Italy - 80133 Napoli

chiarini@uniparthenope.it
Elisabetta Marzano

Department of Economic and Legal Studies

University of Naples, Parthenope

Italy - 80133 Napoli

elisabetta.marzano@uniparthenope.it 


\section{Introduction}

The severity of sentencing as an instrument to deter crime has long be discussed. Often, this debate is related to the different contexts, crimes and legislation, so that it becomes difficult to understand whether an increase of the penalty or sanction, can produce a sufficient deterrence to limit the crime. This difficulty is made even more complicated by the fact that, in some countries, although the sanction exists, legislation can not endure it fully. It is seemingly public opinion that severe and harsh sentences are required to prevent future crime. Deterrence is based on the premise that humans are 'rational' being able to measure the advantages and disadvantages of their actions. As a result, the pain of punishment must be equal to or more than the pleasure/benefits of crime in order to deter the public/individual from choosing to commit a crime. This is the economic approach to crime behaviour (see amongst others Cook at al 2013). There is a growing acceptance that people commit crimes for reasons other than some rational decision-making process (psychological, social, etc.). ${ }^{2}$ This may be less true for some economic crimes such as fraud or tax evasion, where an agent rationally calculates the costs and the benefits of crime. In this context, we are not considering

\footnotetext{
${ }^{2}$ A fundamental question in economics of crime research and policy is whether tougher sentencing deters crime. In various guises, the question has been around a long time, with the notion in the economics of crime literature being that tougher sentences, and maybe sending more people to jail or prison, have scope to deter crime by individuals who would, in the presence of weaker sanctions, engage in crime. The idea that severity of punishment could have a deterrence effect on crime dates back to Beccaria (1764) and it is incorporated in the Becker (1968) framework on the economics of crime. See Freeman (1999) for a review. Persuasive empirical evidence on the question is hard to find and the reasons are among the most varied. Often, it has been found that the deterrent effect exists more with the certainty of punishment, than the severity of punishment. Between the vast literature see also MacGuire (2004), Bell et al (2013), and Mastrobuoni and Rivers (2016).
} 
remorseless killers who grew up in poor, violence-ridden neighbourhoods, but crime may be similar to work, an activity that competes in use of time with other activities (Ehrlich 1973), although with a risky set of consequences. This perspective leads naturally to a presumption of deterability - that crime rates will be inversely related to the likelihood and severity of punishment. In this case, the strategic aspect comes into play and deterrence (severe and harsh sentences) can influence the solution of the game. Thus, the strategic aspects do interest this work, which is aimed to understand whether increased penalties for an economic crime such as tax evasion may limit this phenomenon and whether this may be a policy strategically relevant. In order to analyze this aspect, as well as the crime behavior, and to show how the probabilistic interpretation of strategic behavior can be tricky, the "the inspection game" proposed several years ago by George Tsebelis, is here used.

The crime games usually have not pure strategy Nash equilibria. Conversely, criminals and crime prevention institutions (controller, inspector, police, tax inspector etc.) randomize their strategies. In fact, the feature of a criminal action is based on a probability distribution, it is random by definition, as well as a control by the police or a crime prevention institution is necessarily random. Thus, mixing between strategies seems plausible for these players. The random decision may concern which place to control (traffic light; house, parking, banks, taxpayers, firms etc.), the conciseness and the frequency of audits. In this case mixing between strategies seems plausible. However, in the crime games and, in particular, in the game of tax evasion, the players do not randomize in practice. The complete information game payoffs are understood as an approximate description of the strategic situation, but they do not capture every consideration in the mind of the players. Because of players have some small private inclination to choose one actions, or another independent from the specific payoffs, they will not be indifferent between their actions, but will almost always be choosing a strict best response. Therefore, the interpretation of Tsebelis, and the literature on crime based on randomizing agents, is at least misleading. 
This paper is structured as follows. In Section 2 we introduce the basic crime game, highlighting the shortcomings of some interpretations. Section 3 investigates the tax evasion game. In Section 4, we report on the possible interpretation of crime mixed strategy Nash equilibrium, emphasizing its correct reading as a perturbed (private information) equilibrium. Section 5 reports the Italian experience in terms of the severity of the sentence and the certainty of punishment for the tax evasion crime. Concluding remarks are provided in Section 6.

\section{The Robinson Crusoe fallacy and the failure of severity of penalty}

In several papers published more than two decades ago, Tsebelis (1989; 1990a; 1990b), stressed the Robinson Crusoe fallacy: threating a problem of game theory as a problem for decision theory. In the former, agents act against rational players instead of against nature. In other words, the probability distribution linked to the strategies are not exogenous but change with those of the rational opponent. The paper focused on a 2x2 game played by a person who violates the law and the inspector (the inspection game) with a unique mixed-strategy Nash equilibrium.

The mixed strategy equilibrium of the crime game predicts a surprising conclusion: any attempts to increase the severity of punishment will alter the payoff of the individuals (for instance thief and police officer), leaving unchanged the frequency of violation at equilibrium. The game approach to crime problem suggests that the predisposition of a policy in crime deterrence is a fact rather complex and, in any case is not easily detectable in the severity of the penalty. Thus the Becker's approach, characterized by the absence of strategic behavior is not a valid framework at least for setting a policy design. This simple game works as follows: 
Figure 1: Tsebelis’ crime game.

\begin{tabular}{ccc|}
\multicolumn{1}{c}{} & \multicolumn{1}{c}{ Enforce } & \multicolumn{1}{c}{ Not } \\
\cline { 2 - 3 } Offend & $a_{1}, a_{2}$ & $b_{1}, b_{2}$ \\
\cline { 2 - 3 } Not & $c_{1}, c_{2}$ & $d_{1}, d_{2}$ \\
\cline { 2 - 3 }
\end{tabular}

A criminal player decides whether offend (or violate a given law) or Not offend. The inspector player might enforce a law or Not. Each of these decisions provides a payoff inserted in the matrix (2x2 game) of Figure 1. The entries of the matrix fulfill the restrictions $c_{1}>a_{1}, b_{1}>d_{1}, a_{2}>b_{2}, d_{2}>c_{2}$. In other terms, the police prefer to enforce the law when it is violated and vice versa. This latter preference is due, of course, to the costs of enforcement. The criminal prefer to offend if police play not enforce. There are not pure strategies Nash equilibria. The (unique) mixed strategy equilibrium of the game is:

$$
p^{*}=\frac{d_{2}-c_{2}}{a_{2}-b_{2}-c_{2}+d_{2}} \quad ; \quad q^{*}=\frac{b_{1}-d_{1}}{b_{2}-d_{1}-a_{1}+c_{1}}
$$

As theorems 2 and 3 of Tsebelis (1989) state, an increase in the penalty leaves the frequency of violation of the law at equilibrium unchanged whereas an increase in the penalty decreases the frequency that the police enforce the law at equilibrium. Intuition is simple, since the agents can not be assimilated to a probability distribution over states of world, an increase in the penalty affect in the short run the criminal who reduces violations of the law, the police realize this change in criminal behavior and modify their own strategy, trying to reduce the frequency of law enforcement. At this point, the criminal will modify again and the new equilibrium will be the one predicted by equations (1). Several authors have reformulated the inspection game proposed by 
Tsebelis, using different assumptions on the payoffs of the game and different game models (see Pradiptyo 2007; Andreozzi 2004 and 2008). ${ }^{3}$

While in general the Robinson Crusoe fallacy is appropriate (the use of decision theory in describing problems that belong to game theory), the conclusion on the crime game is at least misleading. Tsebelis' assumption of independence between the payoffs, which characterizes the game is not realistic in a crime game. It is true that the probability of law enforcement is not given exogenously, but derives from the rationality assumption and from the payoffs of the players. However, these payoffs are not independent. In the first mixed strategy $p^{*}$, in fact, the payoff $a_{1}$ is not included, but $a_{1}$ is necessarily correlated with $a_{2}$, and then, an increase of the penalty produces an increase of $a_{2}$ that generates, in equilibrium, a reduction of the probabilities of committing a crime. Since the agents maximize against each other and not against nature (as in decision theory), their acts are not independent so as their payoffs, as stated by the restriction of the game.

\section{Tax evasion game}

This is well showed by the Corchòn (1992) tax evasion game. An economic crime in vogue in several countries: ${ }^{4}$

\footnotetext{
${ }^{3}$ For instance Andreozzi (2004, 2008) discusses a variant of Tsebelis' inspection game in which the inspector acts as a Stackelberg leader and an evolutionary model where tha game is played repeatedly by pairs of individuals drown at random from two large populations of individuals and police.

${ }^{4}$ Illicit work and all the other activities in the shadow economy, which exist in part as a means of evading taxes, has grown increasingly in Europe in the last decades. See Schneider (2013).
} 
Figure 2: Tax-evasion game.

\begin{tabular}{c|c|c|}
\multicolumn{1}{c}{ Enforce } & \multicolumn{1}{c}{ Not } \\
\cline { 2 - 3 } Evade & $Y-T(1+d), T(1+d)-c$ & $Y, 0$ \\
\cline { 2 - 3 } $\operatorname{Not}$ & $Y-T, T-c$ & $Y-T, T$ \\
\cline { 2 - 3 }
\end{tabular}

Here the restrictions are $Y>(Y-T)>Y-T(1+d) ; \quad c<d T ; \quad T(1+d)-c>T>T-c>0$. In this game, of course, the utility is money and the monitoring authority is the Revenue Agency. $Y$ represents the income, $T$ the amount of tax due and $d T$ the fine get by the evader if he is caught. Finally, c is the cost of monitoring and conviction. As it is well known the game has no pure strategy Nash equilibria. The two players mixed strategies that are optimal responses to each other are:

$$
p^{*}=\frac{c}{T(1+d)} ; \quad q^{*}=\frac{1}{1+d}
$$

An increase in the penalty rate $d$ decreases the probability to commit the economic crime and, affecting positively the Revenue Agency equilibrium payoff $\left(T-\frac{c}{1+d}\right)$, it is a Pareto improvement policy. The mixed strategy (2) also shows that increasing incentive for inspector to play enforce does not leave the frequency of inspector $q^{*}$ unchanged and reduces the frequency of law infraction $p^{*}$. Thus, it is true that increasing the severity of the penalty reduce the frequency of the 
inspections. It is well known, since Becker (1968), that an institution or a policy-maker concerned with maximizing the expected utility of a representative citizen will want to set the penalty for detected crimes as high as possible, so that even with a low resource cost of enforcement, the overall expected deterrent effect will be large. ${ }^{5}$ Rules, with severe penalties and certain in their application are in fact preferable to costly discretionary policies: a result, in fact, confirmed by the strategic analysis.

In Tsebelis crime game, the absence of an impact of penalty on crime is due to the independent payoff spaces of the two players, and although in many crimes the utility-disutility cannot be directly monetized, as in the tax-evasion game, the payoffs of the involved agents cannot be independent. The players mixed strategies depend upon the payoffs but these latter are related in such way that any change in criminal payoffs would not leave his choices unaltered.

\section{Interpretation of crime mixed strategy Nash equilibrium}

However, the most interesting aspects that comes from strategic analysis lies in the following questions: why players should randomize and how we can interpret these strategies. In this case, players committing to a random device that probabilistically selects components of their set of actions seem an appropriate assumption. If the control costs are important, then inspectors may decide randomly to audit the "social situations" of the public. However some problems arise, because against the pure strategies, mixed strategies are very sensitive to payoffs. But a small alterations in penalty will not dramatically change the behavior of players (criminals and inspectors)

\footnotetext{
${ }^{5}$ Of course, this argument ignores, inter alia, the possibility of a corrupt tax administrator who abuses the system or, alternatively, harshly punishes someone who make an honest mistake. Hence the harsher the penalty, the more detailed and cautious the prosecution process must be.
} 
and therefore such a variation should be buffered to some extent. Moreover, a mixed strategy equilibrium is not very sensitive to a change of strategies. As shown below, if the criminal plays the equilibrium strategy $p^{*}$, then the police can choose any probability $0 \leq q^{*} \leq 1$ and the criminal receives the same payoff: this is the distinctive feature of the equilibrium in mixed strategies, but a question emerges, are we confident that the strategic interaction of a crime should be modeled with mixed strategies?

\subsection{A not attractive equilibrium}

Thus, the mixed-strategy equilibrium seem appropriate for crime games but it provides an awkward solution because it is fundamentally unstable. To illustrate this, it is possible consider again the tax evasion mixed strategy equilibrium (2). The evader equilibrium strategies assigns the probabilities:

$$
p^{*}=\frac{c}{T(1+d)} ; \quad\left(1-p^{*}\right)=\frac{T(1+d)-c}{T(1+d)}
$$

to his two pure strategies Evade and Not, respectively. The Revenue Agency equilibrium strategies assigns the probabilities:

$$
q^{*}=\frac{1}{1+d} ;\left(1-q^{*}\right)=\frac{d}{1+d}
$$

to its two pure strategy, Enforce and Not, respectively. Adding a new row and a new column to the payoff matrix of Figure 2 corresponding to the mixed strategy payoffs, we have the following matrix: 
Figure 3: Tax evasion game with mixed strategy payoffs.

\begin{tabular}{c|c|c|c}
\multicolumn{1}{c}{ Enforce } & Not & Mixed \\
\cline { 2 - 4 } Evade & $Y-T(1+d), T(1+d)-c$ & $Y, 0$ & $Y-T,(T(1+d)-c) / 1+d$ \\
\cline { 2 - 4 } Not & $Y-T, T-c$ & $Y-T, T$ & $Y-T,(T(1+d)-c) / 1+d$ \\
\hline \multirow{3}{*}{ Mixed } & $\begin{array}{c}(Y-c-T) T c / T(1+d) ; \\
\left(T^{2}(1+d)-T c\right) / T(1+d)\end{array}$ & $\begin{array}{c}(T(1+d)(Y-T)+T c) / T(1+d) ; \\
\left(T^{2}(1+d)-T c\right) / T(1+d)\end{array}$ & $Y-T,\left(T^{2}(1+d)-T c\right) / T(1+d)$ \\
\cline { 2 - 4 } &
\end{tabular}

It is now clear that if the evader expects the Revenue Agency to use its mixed equilibrium strategy Mixed, he will have no incentive to use his equilibrium strategy Mixed: in fact, he will obtain the payoff $Y$ - $T$, with all his own strategies. The Revenue Agency too has not a real reason to use his mixed strategy, also in the case in which the tax dodger choose the mixed strategy. It will obtain always the same payoff: $\frac{T^{2}(1+d)-T c}{T(1+d)}$. Thus, certainly, there is no reason to consider (Mixed, Mixed) an attractive equilibrium (see, Harsanyi 1973; Harsanyi and Selten 1988).

\subsection{A perturbed (private information) equilibrium}

It seems that the only reason a dodger randomizes is to keep the Revenue Agency in equilibrium and the only reason the tax agency randomizes is to keep the tax evader in equilibrium, but why would these players want to do this? This equilibrium is an idealization, as players in crime games typically have at least a slight amount of incomplete information about the others' objectives. 
While this equilibrium determines which are the vectors of the a priori probabilities assigned by players to each strategy, it is nevertheless true that, in the aftermath, they will play any combination of pure strategies, and not necessarily the one who is credited with the highest probability.

Consequently, the payoff that each of them will receive in equilibrium will be the one associated to the outcome of the game in pure strategies, not the one expected, calculated using the probabilities. However, although an irreducible minimum of uncertainty remains, the Nash equilibrium in mixed strategies provides us with the necessary information on equilibria in pure strategies that will be played: if, for instance, the monitoring or audit costs are very high, then the equilibrium in pure strategies more likely is (Evade, Not). Conversely, if the penalty is very high and outweigh the costs, then the equilibrium in pure strategies that will be played by rational agents is (Not, Enforce).

A realistic crime strategic model will not have fixed payoffs but rather randomly fluctuate payoffs. In fact, there seems to be almost general agreement that game theory's agents are excessively rational and well-informed in comparison with their real-life counterparts. Such a game will not provide mixed strategy equilibria, as shown by the Harsanyi’s (1973) “purification” result. Dodgers and Revenue Agency always find that one of their two pure strategies will yield them a higher expected payoff, therefore, they will actually use these pure strategies.

We assume that a component of the penalty and a component of the costs are private information, as in following Figure 4, where $\mu$ and $v$ are the two random components respectively for the dodger and the Revenue Agency. In other word, both $\mu$ and $v$ are independent draws from a uniform distribution $\mu \approx\left\lfloor\mu^{+}, \mu^{-}\right\rfloor$and $v \approx\left\lfloor v^{+}, v^{-}\right\rfloor$. 
Figure 4. Tax evasion game with private information

\begin{tabular}{c|c|c|}
\multicolumn{1}{c}{ Enforce } & \multicolumn{1}{c}{ Not } \\
\cline { 2 - 3 } Evade & $Y-T(1+(d+\mu)), T(1+d)-(c+v)$ & $Y, 0$ \\
\cline { 2 - 3 } $\operatorname{Not}$ & $Y-T, T$ \\
\cline { 2 - 3 } & $Y-T, T-(c+v)$ & $Y$ \\
\cline { 2 - 3 }
\end{tabular}

Thus, these players have some minor private information about their own payoffs which are omitted from the description of the game. Since the game has not pure strategies equilibria, one should aspect that a player's optimal strategy may be determined by some minor factor that he observes independently of the other player. For the Revenue Agency, the private information certainly involves costs, whereas for taxpayers the spectrum of possibilities can be wider, it can be related to any subjective considerations on the possibility to appeal against the sanctions, and any discounts on the due penalties for accepting the compliance process (often the certainty of punishment is itself a random event). The part of the sentence which constitutes private information of the dodger may be his perception on the actual application of the penalty itself. This is an aspect that we are going to see in the remainder of this section and in Section 5, where we will consider the Italian case.

Thus, we may think that $\mu$ and $v$ can take two values $\left(\mu^{+}, \mu^{-} ; v^{+}, v^{-}\right)$, one positive ( $\left.\mu^{+}>0 ; v^{+}>0\right)$ and the other negative $\left(\mu^{-}<0 ; v^{-}<0\right)$, and that they have a probability (common knowledge) equal to $1 / 2$ each to present. At this point it is clear that the evader plays EVADE when $\mu^{-}$is negative and NOT when this value is positive. In a similar manner the Revenue Agency will opt for ENFORCE when $v^{-}$is negative and plays NOT when this value is positive. With these “cut-point” strategies, the Bayesian equilibrium for this four-players game satisfies: 
i) taxpayer $\mu^{+}$uses the equilibrium strategy NOT;

ii) taxpayer $\mu^{-}$uses the equilibrium strategy EVADE;

iii) $\quad \mathrm{RA} v^{+}$uses the equilibrium strategy NOT;

iv) RA $v^{-}$uses the equilibrium strategy ENFORCE.

Obviously, as $\mu^{i}$ and $v^{i}$ go to 0 , this equilibrium converges to the unique (mixed strategies) equilibrium of the two-players game in Figure 2 in which the taxpayer chooses EVADE with probability $p^{*}$ and the Revenue Agency chooses ENFORCE with probability $q^{*}$ reported in equation (2).

For dishonest taxpayer types $\mu^{i}$, the optimal choice is:

$$
\begin{array}{lll}
\mu^{+}: & Y-T>Y-\frac{1}{2} T\left(1+d+\mu^{+}\right) & \text {NOT } \\
\mu^{-}: & Y-T<Y-\frac{1}{2} T\left(1+d+\mu^{-}\right) & \text {EVADE }
\end{array}
$$

For the Revenue Agency types $v^{i}$ the optimal choice is:

$$
\begin{array}{lll}
v^{+}: & T>T+\frac{1}{2} d-\left(c+v^{+}\right) & \text {NOT } \\
v^{-}: & T<T+\frac{1}{2} d-\left(c+v^{-}\right) & \text {ENFORCE }
\end{array}
$$

The Nash equilibrium that involves randomized strategies can be interpreted as limit of Bayesian equilibria in which each player is choosing a pure optimal action. In this equilibrium, the evader and the tax office do not play a mixed strategy and no player expects his opponent play a mixed strategy: the probability equal to $1 \frac{12}{2}$, attributed to the fact that the other player opts for EVADE or ENFORCE, derives from the existence of a probability equal to $1 / 2$ to meet a player who has a 
preference, respectively for EVADE and ENFORCE. The Bayesian equilibrium (3)-(4) indicates that the higher is the perception that the punishment (however harsh) will not be applied, the more the effect of sanctions will be neutralized, increasing the likelihood that the taxpayer will become a tax evader. From the Revenue Agency point of view, the higher are the monitoring and sanctioning costs (or the more inefficient and ineffective are these services) the more likely is that the agency limits its controls. Also, from the strategic setting emerges that for the RA, its effectiveness in the controls (and therefore its costs) should be "common knowledge" if its type is $\mu^{-}$: thus, the tax agency successes in terms of formal controls of tax returns, audits, investigations, and higher tax assessed, as well as technological innovations that help to limit personnel and reduce costs, raising the agency's efficiency, help to define the most favorable equilibrium for the AE, and should be common knowledge rather than private information. On the contrary, in the taxpayer point of view, is crucial that its perception remains private information. Finally, an important policy implication concerns the ability to enforce the sanctions, that is, the certainty of punishment. If this capacity is low and it is "common knowledge", then it is likely that tax evasion is massive.

\section{The Italian experience: "handcuffs to the dodgers"}

In Italy the severity of the sentence and the certainty of punishment have played a significant role in the determination of compliance. The latest official estimates indicate a figure of about 250 billion euro for the value added tax base hidden to the Revenue Agency (MEF, 2013). The National Institute of Statistics, consistent with international standards and, in particular, with the 1995 System of National Accounts, estimates and regularly updated a time series of the size of the underground economy from 2000, and indicates an hidden production over $16 \%$ of the total GDP. In the early '80s, the need for resource recovery (with the difficulty to control public spending) had led governments to an "authoritarian way" to solve the problem of tax evasion, with the law called 
“handcuffs to dodgers” (DL 10/07/1982, n. 429, converted into L 07.08.1982, n. 516). Tax evasion became a crime (see Bricchetti and de Ruggero 1995). The offense of non-payment of withholding tax had, however, generated hundreds of thousands of complaints with the Public Prosecutors of the Republic, burdening the Courts and Tribunals. The arrest of the activities in the Courts and in the Tribunals, the political discontent of many categories of self-employed workers and entrepreneurs, along with different kind of fiscal amnesties (in particular on VAT and income tax) that have taken place over the years (since 1973, there have been at least 26 amnesties), have effectively ensured the substantial impunity and, therefore, the failure of the law on the severity of the penalty (see Manestra 2010). The legislation has essentially failed the goal: its poor selectivity ended up flooding the prosecutors in crime reports for formal and minimal unlawful conduct, resulting in virtual impunity for the evaders that only a few cases have incurred the penalty of imprisonment. By contrast, the office charged were started by small taxpayers, with thousands of judicial procedures to largely fall into prescription.

In this context, there is no surprise that the equilibrium that has been established in the Italian economy is (EVADE, NOT). However, this equilibrium does not report a failure of the severity of the penalty, rather the inability of the Italian governments to enforce it. The Italian experience shows that strategic prescriptions alone cannot solve the tax evasion problem, and that creditworthy institutions must take into account the organizational, legal, bureaucratic and cultural aspects which are not defined by the game.

\section{Concluding Remarks}

A fundamental question in economics of crime research and policy is whether tougher sentencing deters crime. The debate was often intertwined with the notion that swiftness and certainty of the 
penalty outmatch severity. This question has been around a long time, with the notion in the economics of crime literature being that tougher sentences, and maybe sending more people to jail or prison, have scope to deter crime by individuals who would, in the presence of weaker sanctions, engage in crime. The severity of punishment may influence behavior, if potential offenders weigh the consequences of their actions and conclude that the risks of punishment are too severe. One problem with deterrence theory is that it assumes that human beings are rational actors who consider the consequences of their behavior before deciding to commit a crime; however, this is often not the case. For example, a large percentage of prisoners were under the influence of drugs or alcohol at the time of their offense (see amongst others, Durlauf and Nagin, 2011 for a survey on deterrent effects of imprisonment).

If we consider some economic crimes such as tax evasion, using the strategic analysis is certainly true that high fines and even arrest and jail, exerts a strong deterrence. In this context, the taxpayers' decision to evade taxes or not, is rationally taken and planned possibly with their accountants or business consultants, considering advantages and disadvantages. This obviously can not be true for other types of crime related, for instance, to social and psychological factors. Regarding the strategic analysis, the crime game can not be simply read with mixed strategies. These are inconclusive on how the players act rationally. So, the original framework of the Tsebelis' crime game contains an excessive restriction (that of independent payoff) and may not otherwise be generalized to economic crimes.

We have described why the "handcuffs to dodgers" policy has failed in Italy in the early '80s. The inability of the Italian governments to enforce it, led the dishonest taxpayers to a high perception of a low certainty of punishment. When the key features of a player such as the Revenue Agency and/or the government, that should be private information become common knowledge, then the unique equilibrium can only be supported by a high tax evasion. 


\section{References}

Beccaria, C. (1764) On Crimes and Punishments, TreatiseTrans. Henry Paolucci, Englewood.

Becker, G., (1968) Crime and Punishment: An Economic Approach, Journal of Political Economy, 76, 169-217.

Bell B., Jaitman L. and Machin S. (2013), Crime deterrence: Evidence from the London 2011 riots, mimeo, University of Oxford and Centre for Economic Performance, London School of Economics, $1-44$.

Bricchetti R. and de Ruggero L. (1995), I reati tributari, Pirola Legale,Milano.

Cook P.J., Machin S., Marie O. and Mastrobuoni G. (2013)(eds), Lessons from the Economics of Crime, MIT Press, Cambridge.

Corchòn L.C. (1992), Tax evasion and the underground economy, European Journal of political economy, 8, 445-454.

Durlauf, S. N. and D. S. Nagin (2011) The Deterrent Effect of Imprisonment, in Controlling Crime: Strategies and Tradeoffs, (Eds.) P. J. Cook, J. Ludwig, and J. McCrary, University of Chicago Press. Chicago.

Freeman, R. (1999) The Economics of Crime, in O. Ashenfelter and D. Card (eds.) Handbook of Labor Economics, North Holland.

Harsanyi J.C. (1973), Games with randomly disturbed payoffs: A new rationale for mixed-strategy equilibrium points, International Journal of Game Theory, 2, 1-23.

Harsanyi J.C. and Selten R. (1988), A General Theory of Equilibrium Selection in Games, MIT Press, Cambridge.

Manestra S. (2010), Per una storia della tax compliance in Italia, Questioni di Economia e Finanza (occasional Papers) N. 81, Banca d’Italia.

MacGuire J. (2004), Understanding Psychology and Crime. Perspectives on Theory and Action, Open University Press, Maidenhead, UK.

Mastrobuoni G. and Rivers D.A. (2016), Criminal discount factors and deterrence, IZA Discussion Papers N. 9769.

MEF (2013), Ministero dell'Economia e delle Finanze, Nota di Aggiornamento del Documento di Economia e Finanza 2013, Roma.

Pradiptyo R. (2007), Does punishment matter? A refinement of the Inspection Game, Review of Law and Economics, 3, 197-219. 
Schneider F. (2013), The shadow economy in Europe, 2013, ATKearney and Kepler University.

Tsebelis G. (1989), The abuse of probability in political analysis: the Robinson Crusoe fallacy, American Political Science Review, 83, 77-91.

Tsebelis G. (1990a), Penalty has no impact on crime: A game theoretic analysis, Rationality and Society, 2, 255-286.

Tsebelis G. (1990b), Are sanctions effective? A game theoretic analysis, Journal of Conflict Resolution, 34, 3-28. 